\title{
9. Connecting EAI-Domains Via SOA-Central vs. Distributed Approaches to Establish Flexible Architectures
}

\author{
Marten Schönherr \\ Technical University of Berlin \\ Department of Business Informatics \\ Competence Center EAI \\ [schoenherr@sysedv.tu-berlin.de]
}

\begin{abstract}
The article defines adaptability as the main target to solve the problem of enterprise architecture sustainability. Flexibility is an important steering mechanism to develop adaptability. Organisational modularisation is used to flexibilise enterprise structures. Business processes are changing permanently according to business requirements. Unfortunately it is a matter of fact that IT is disabling this business-driven change. Integration Technology is being introduced to improve the situation. Establishing step by step a multi service integration architecture creates new issues as handling internal charging routines, service monitoring and service life cycle management. The CC for EAI at Technical University is working on an approach and prototype of a service management module adressing the mentioned issues. ${ }^{46}$
\end{abstract}

\section{INTRODUCTION: NECESSITY OF FLEXIBLE ENTERPRISE ARCHITECTURES}

The system "enterprise" is exposed to complex changes of its environment. The three essential environmental dimensions are complexity, dynamics and interdependence (Jurkovich, 1974: 380). As described in figure 1 particularly the dimensions complexity and dynamics (Krystek, 1999: 266) increased by current developments like globalisation and automation (Frese, 2000) confront companies with diverse problems.

To solve the problem they have in principle two possibilities to react (Kieser \& Kubicek, 1992):

- They can take measures to influence the environment with the target to reduce dynamics and complexity by decreasing the interdependences.

- Or they can increase the adaptability of the enterprise.

In this article the second aspect - the increase in adaptability - is continued to be examined. For this the architecture components organisation and IT are brought into reference with each other after characterising the flexibility as a planning target in order to draw up an approach for the modularisation of the organisation and ITarchitecture within the context of Enterprise Application Integration (EAI).

\footnotetext{
${ }^{46}$ This paper has been previosly presented in a poster session at IFSAM 2004/Goeteborg/Sweden.
} 


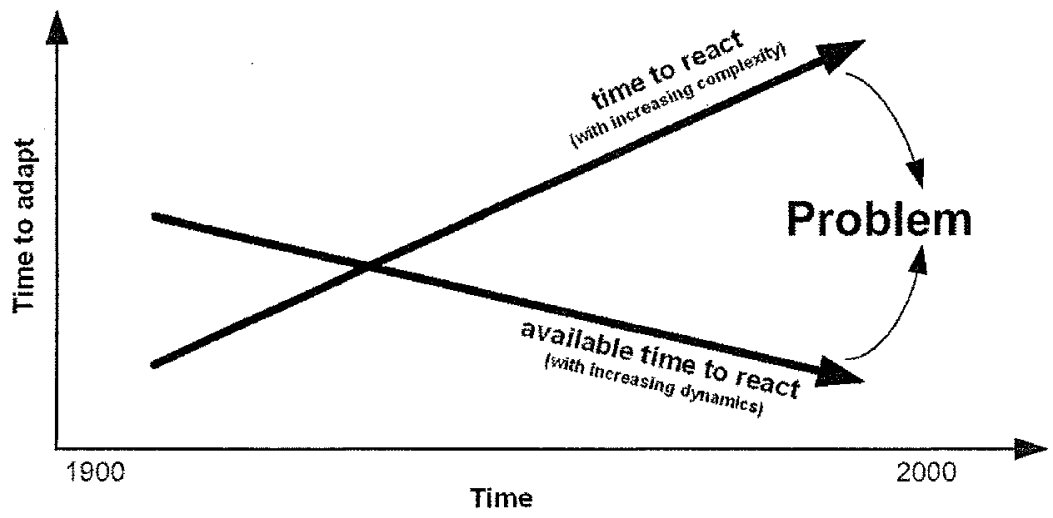

Figure 1. Complexity and dynamics as a current management problem

\section{FLEXIBILITY AS AN ORGANISATIONAL TARGET}

The understanding that "enterprise modification has changed or will have to change from an event, which has to be organised in longer time intervals, into a permanent state" (Krueger, 1998: 227) is accepted today to a large extent. The task is now to make companies more flexible for this change. Krueger distinguishes the change of companies depending on the requirement, willingness and capability of change. (Krueger, 1998: 227) The capability of change represents the core of the considerations of this article. In order to deal effectively with internally and externally caused requirements of change corresponding structures and organisational instances for the institutionalisation of change are to be created in the companies. In addition to institutional measures structural measures to increase the capability of change - measures for an increase in flexibility - are discussed in the following. The term of flexibility comes from Latin and means changeability, agility or ductility. A system is flexible if a requirement of change is completed by a potential of change in the system, which can be activated in an appropriate time (Kieser \& Kubicek, 1992; Gronau, 2000: 125). The requirement of change includes a factual and a temporal dimension. The temporal dimension not only requires the ability to react of an enterprise but also the capability of anticipative adaptation. Hill/ Fehlbaum/ Ulrich describe this as productivity of second order (Hill, Fehlbaum \& Ulrich, 1994). Kieser/ Kubicek identify the following tendencies of the structure of companies as suitable to increase their flexibility (Kieser \& Kubicek, 1992):

- low specialisation on jobs and department level

- strong decentralisation

- flat hierarchies

- minimisation of strength of central supporting departments (staffs)

- simple, which means no extensive matrix structures

The mentioned tendencies aim at decoupling the structures and processes by means of a reduction of interfaces. In the following, these thoughts are further developed in 
order to facilitate decoupling and flexible reconfiguration through modularisation on different levels of the enterprise.

\section{ORGANISATION AND IT}

Today it is not sufficient to exclusively consider formal organisational planning aspects when making companies more flexible. It is rather necessary to consider the technological aspects and to combine both in an integrated architecture approach. The other way round it does not make sense to introduce or change information systems without considering the interactions with the tasks and processes, which they support (Kaib, 2002; Derszteler, 2000). EAI does not only integrate IT-systems, but is particularly the cause to plan the domain organisation and IT in an integrated way and to commonly develop them further. In the science this discussion about the mutual interdependences of IT and organisation of the enterprise has a long tradition, in which not only the technology (technological imperative), the organisation (organisational imperative) but also the complex interactions between both (emergent perspective) (Markus \& Robey, 1998: 583) have been described as driving factors (Leavitt \& Whisler, 1958: 41; Applegate, Cash \& Miles, 1988: 128; Rockart \& Short, 1989: 7; Burgfeld, 1998). Following Frese it is not assumed here that information technology and enterprise organisation are in a deterministic causeeffect context (Frese, 2000). It is rather assumed that IT represents an option which increases the scope or planning of the organizer (Frese, 2002: 191).

\subsection{Modular Enterprise Architectures}

In this context, enterprise architecture is understood as the interaction of technological, organisational and psycho-social aspects at the development and utilization of operational socio-technological information systems (Gronau, 2003). In the following, above all, the technological and organisational domains are considered as IT- and organisation architectures. A currently discussed method to make IT- and organisation architectures more flexible is the modularisation. By means of system perspectives in the following general characteristics of modules are described, which are taken from the organisation and IT-literature and which are equally to be valid here for both areas. A module consists of two parts, the module interface and the module trunk. The module interface contains the specification of the performances of the module, which are necessary for its environment for "utilization". The module trunk implements the specified performances. Modularisation means the structuring of a system in small, partial-autonomous subsystems. The complexity reduction in this results from the system formation within the system enterprise (Krcal, 2003: 3). The subsystem formation has a complexity-reducing effect, because on the one hand it conceals the subsystem internal complexity in the sense of the encapsulation from the system environment and on the other hand it causes a decoupling of the subsystems through the reduction to few known interfaces. The higher flexibility of the architecture results form the easier reconfiguration possibility of the decoupled modules. Thus, complexity reduction can be considered as prerequisite for making architectures more flexible. At the modularisation the following organisation targets are to be taken into consideration (Rombach, 2003: 30; Lang, 1997):

- Abstraction form implementation 
- Encapsulation in the sense of concealing the internal functioning

- Exchangeability

- Reusability

- temporal validity

- Orthogonality (in the sense of "not influencing each other")

- no overlapping

- Completeness (conclusion)

- well-defined interfaces

- Interface minimalism

- Generality

By using these principles modules are created, which potentially can be combined, reused and easily changed (Rombach, 2003: 30). In the following, it is shown which approaches result from the modularisation of the organisation and IT.

\subsection{Modularisation of the organisation}

In the following, the modularisation of the organisation is considered on the level of the whole enterprise as macro level and the on the level of business processes as micro level (demonstrated in figure 2). By defining a macro and micro level two targets are pursued:

- Defining structures and at the same time making them more flexible

- Defining tightly structured and manageable modules

The macro level has a strongly structuring effect on the organisation. The modules of the macro level, the so-called macro modules, are to be stable over a longer period of time. By this, the macro level represents a reference system as foundation for the organisation of the modules of the micro level within the respective macro modules. The modules of the micro level, however, are to reflect the dynamics of the changing process requirements through corresponding reconfiguration. Thus it is the aim to create a reference-creating, stable organisation-invariant level - the macro level - and a dynamic, flexibly configurable level - the micro level. In the following, the characteristics of the macro and micro level are described.

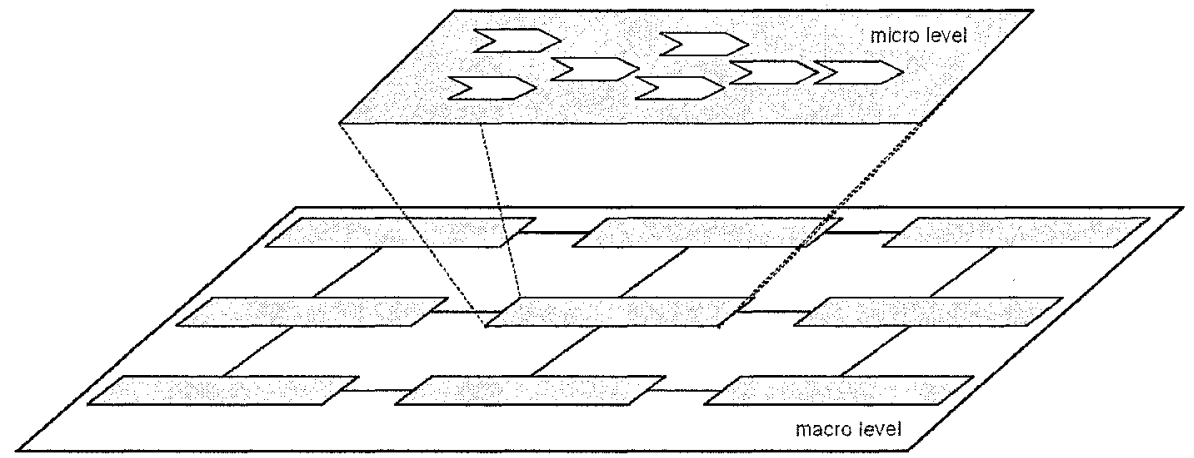

Figure 2. Modularising in macro- and micro level

Modularisation on macro level: In order to achieve a direct reproduction of strategy-oriented organisation structures on the IT-infrastructure more than the classic course- or structure-organisational points of views are required. The target of 
the definition of the macro modules is the consideration of the whole organisation by means of suitable criteria to be able to derive exactly this step. In the following, special criteria for the formation of macro modules are mentioned to complete the above mentioned general criteria:

- Similarity of the processes within a module

- Similarity of the necessary process know-how

- Minimisation of the external interdependences

- Maximisation of the internal coherence

- Independence of operative process adaptations

- Sector-specific best practices for the definition of modules

The enumerated criteria are partially used in the area of component ware in order to determine the granularity of software components. The analogous application on macro level at least leads to similar methods, with which later a match between macro, micro and software architecture level can be achieved. The defined macro module do not represent an instruction for a reorganisation. They rather pursue the target to guarantee a special way of looking at the organisation. This special way of looking at the organisation supports the modularisation of the respective IT-systems, which support the processes of a macro module. On the level of the macro modules structural similarities are to build the foundation for the definition. In addition to the above mentioned criteria, further criteria can be determined depending on the situation. As a rule, processes run through different modules, which means no limitation is made according to the beginning or end of process chains.

Example: In figure 3 it is shown on the basis of a classic matrix organisation, which is composed of sections and functional areas, how macro modules are formed through the above mentioned criteria. In this, the same colourfully highlighted areas respectively represent a macro module. For example, within the different sales organisations two areas were defined as macro module. The reason for this could be that the processes in both areas are very similar and require similar information for implementation.

Modularisation on micro level: Within the defined macro modules now the structural similarities are to be considered in detail. For the IT-system world particularly the business processes existing within the modules are relevant. Here all process steps have to be compared and the ones with the same structure have to be identified. In principle, a business process is composed of different steps. The probability that there are identical steps in an amount of similar process chains is very high. 


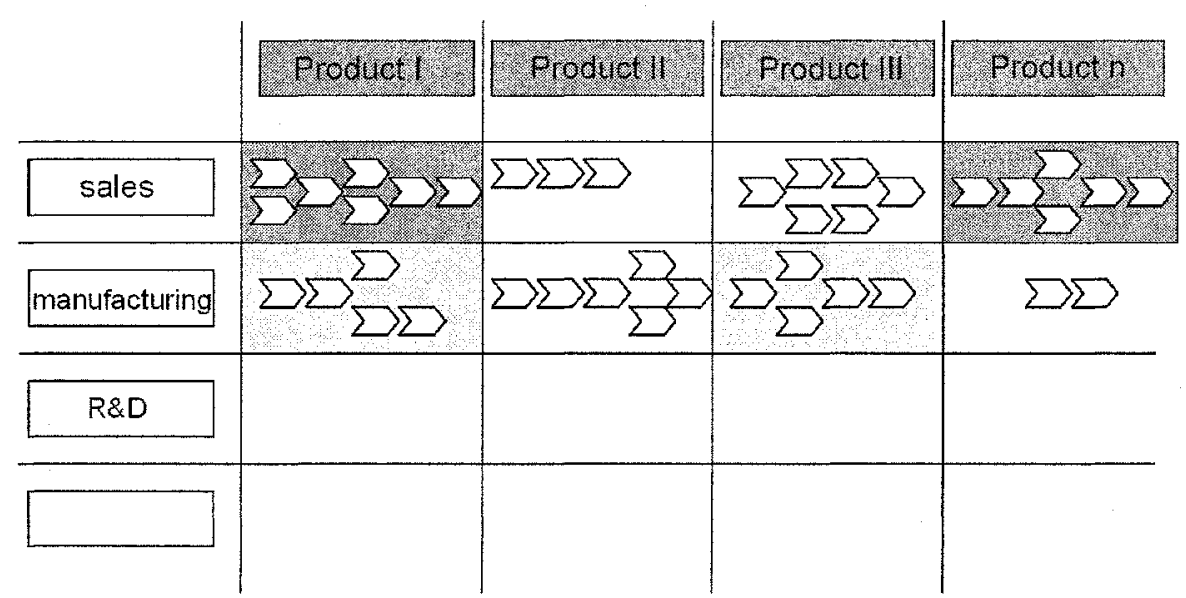

Figure 3. Definition of macro modules in a matrix organisation

Even if the partial processes are slightly different it can be considered if it is possible in the sense of a complexity reduction to modify the actual business processes, that it applies as many partial processes as possible. Gerybadze derives from the methods of modular product organisation criteria for the determination of the degree of modularising capability of processes. According to Gerybadze, there is a good modularising capability if (Gerybadze, 2003: 83):

- for each activity an exactly defined function of the overall system can be defined,

- the quality of the result of this activity can exactly be determined,

- prices or offset prices can be determined for the respective output

- the interfaces can be defined very exactly.

Apart from the general question of modularising capability the determination of the optimal module size is decisive for the successful implementation of the modularisation on process level. Module that are too big can avoid the expected flexibility of the organisation, because the modularisation is to create small, flexible fragments which can be integrated, which are more mobile than an overall monolithic structure. Modules that are too big can restrict the domination of the processes within the module due to their complexity. On the other hand, too many small modules mean a stronger division of labour and partition. The smaller the modules the more specialised the processes naturally have to be within a module. In order to define general criteria to create an optimal size of module, the characteristics of modularisation have to be considered. The minimum size of a module which has to be complied with results from the activities for a clearly definable (interim) product. The maximum module size is determined by the domination of complexity within a module. The complexity may not be so big that the responsible people are no longer able to control the module.

\subsection{Implementation principles}

The implementation of a modular organisation strongly depends on the prevailing conditions of the situation. Essential influence factors are the size of the organisation, its programme of supply, its internationalisation and culture, the 
existing structuring as well as the organisational environment (Kieser \& Kubicek, 1992). In spite of this interdependence on the situation some basic implementation principles can be found:

The main principle is to build small organisational units. They have to be big enough to comprise matching processes to one object (for example, product, product group etc.). With regard to the scope and the complexity, however, they may not exceed the limits of reception and problem-solving capacities of the human being. The process orientation is expressed by the demand to permanently orient the modules to the processes to draw up performances. The process orientation shows that the modularisation does not aim at a function-oriented but an object-oriented structuring.

In close context with the process orientation is the customer or market orientation. According to this all added value activities of the modules are to be oriented to the external and/ or internal customer demands. This results from the main target of the flexible adaptation to the requirements of the market.

Integration of tasks: the processes in a module are to belong together to a great extent depending on their kind in order to guarantee the completeness of the processes concentrated in a module.

Non-hierarchical coordination forms: The coordination of autonomous activity units, which are not in a hierarchical relationship to each other any more, requires new forms of cooperation that are not based on external control any more but on self control.

\subsection{Modularisation of IT}

On the basis of the described modular organisation architecture adequate ITarchitectures are to be defined. The coordinated organisation of strategies, processes and technical infrastructures is a classic subject of business computing science (Wall, 1996). For this different architecture concepts were developed, which have as a target a homology between organisation and IT (Krcmar, 1990: 395; Pohland, 2000; Scheer, 1991).

These concepts, however, are based on the assumption to talk about implementation and new introduction of IT. In order to create lasting architectures, if possible, the paradigm of the structural analogy between organisation and IT should be maintained as far as possible (Gronau, 2003).

EAI vs. service-oriented architecture (SOA) Service orientation and system integration have been discussed independently from each other for many years. EAIplatforms centrally integrate heterogeneous system landscapes on process, method and data level. However, the stronger integration projects are implemented with object-oriented procedures, the stronger seems the closeness to service orientation. The service-oriented application integration can be compared with the integration on interface and method level. It represents an alternative point of view, which attempts to integrate "wrapped" modules from old applications and new applications within a SOA which are already implemented in a service-oriented way. One of the most important objectives of service orientation is the re-utilization of existing components. The prerequisite for this is a central service management, which has to provide functions like service-life-cycle, service distribution and the versioning (Lublinsky \& Farrel, 2003: 30). Since meanwhile the most development tools 
support a service orientation, applications can be developed much easier as services in the future. However, it is frequently difficult to split old applications into modules which can be defined as service. Apart from development environments which actively support a new implementation with service character in the meantime some integration suites also offer tools which make wrapping of old applications in services easier. The costs of this initial transformation can be high and often the intervention in the source code contradicts the strategic guidelines of the responsible IT-staff, who, above all, wants to leave monolithic legacies unaffected (Apicella, 2002). At the consideration of an overall IT-architecture old applications that have to be integrated and planned new implementations have to be assumed. Not only the central EAI-approach but also the decentralised SOA provide methods to implement solutions for the described area of tension. Thus, EAI and SOA are harmonising parts of an overall IT-architecture.

However, within the context of system integration it has to be considered that one of the primary targets of EAI, the reduction of the point-to-point integration scenarios is not replaced by a similar complex SOA. Two main problems at the connection of old applications are standardised interfaces and the granularity of services. At the service-oriented integration of existing applications the granularity of the functions that are packed as services is decisive. Thus, it makes sense to make those functions accessible as services which are generally necessary and thus should be reused. They should carry out a complete working unit and they should be easy to describe in their function and result (Narsu \& Murphy, 2003).

Considering the organisational modularisation on the macro and micro-level there is another advantage which hasn't been described yet. As shown in figure 4 (according to the Credit Suisse Information Bus approach) it is to recommend to implement a tight coupling of applications inside a module. The integration strategy (EAI vs.SOA) of each module depends on the individual situation of the specific module. According to the fact that there are less interactions between modules than inside the module itself with the utmost probability there will be implemented a louse coupling via service-oriented Technology.

\subsection{Service Management}

Establishing a SOA means managing a huge number of business and/or technical services. Web Service based SOA do not offer these features so far. The Competence Center for EAI at the technical University is working on an service management module which for instance supports the whole service life cycle; reuse and service monitoring. The following features are part of the concept developed.

- Services identification

- Service definition

- Definition of service features

- Definition of service granularity

- Defining the Service Provider

- Localise and group services

- Functional oriented domains

- Technology oriented domains

- Application oriented domains 
- Service capsulation

- Service orchestration and allocation

- Service monitoring

To proof the approach the integration lab has established an invironment with 5 commercial EAI-products and a SOA based on Open Source components. An example business case has been implemented to show how service integration can be orchestrated.

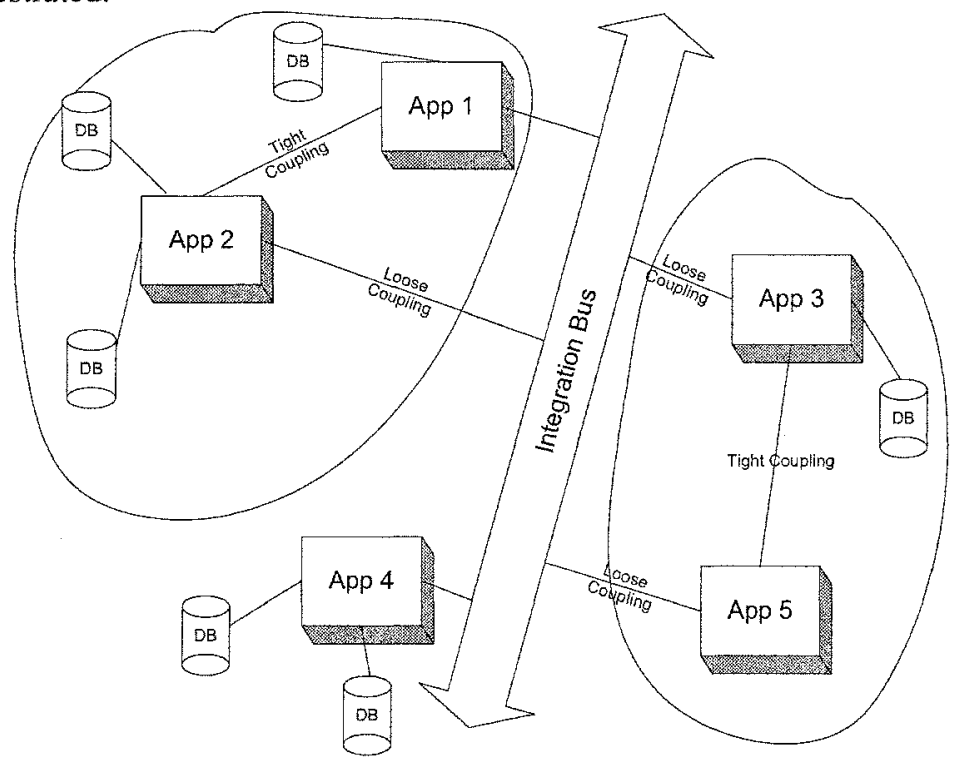

Figure 4. Tight and loose coupling inside and between modules

\section{CONLUSION}

Many publications, which are technically focussed, currently discuss decentralised architectures for the integration of complex IT-infrastructures. Companies again deal with the subject of re-use, although some years ago it almost completely disappeared from the experts discussion under the name of business process repositories, which were planned to implement business processes that can be reconfigured. Platforms with higher performance partly give reason for this unexpected renaissance. The subject EAI also contributes to the current discussion, which is led on an enterprise architecture level. In the first step, it deals with the technical definition of the modules (or services), only in the following, technologies for implementation will play a role. In this sense the article particularly concentrates on the modularisation on a specialist level and its transformation into a technical level.

\section{REFERENCES}

Apicella, M. 2002. Side by side in perfect harmony? InfoWorld Applegate, L.M., Cash, J.I., Miles, D.Q. 1988. Information technology and tomorrow's manager. Harvard Business Review 66, p 128-136 
Burgfeld, B. 1998. Organisationstheorie und Informationstechnologie. DUV, Wiesbaden

Derszteler, G. 2000. Prozessmanagement auf Basis von Workflow-Systemen. Josef Eul, Lohmar, Koeln

Erlikh, L. 2003. Integrating legacy into extended enterprise: Using web services. Relativity Technologies.

Frese, E. 2000. Grundlagen der Organisation: Konzept - Prinzipien - Strukturen. 8 edn. Gabler, Wiesbaden

Frese, E. 2002. Theorie der Organisationsgestaltung und netzbasierte

Kommunikationseffekte. in: Frese, E.; Stoeber, H. (eds.) 2002. E-Organisation. Gabler, Wiesbaden, p 191-241

Gerybadze, A. 2003. Strategisches Management und dynamische Konfiguration der Unternehmens-Umwelt-Beziehungen. in: Leisten, R.; Krcal, H.C. 2003. Nachhaltige Unternehmensführung - Systemperspektiven. Gabler, Wiesbaden, $\mathrm{p}$ 83-100

Gronau, N. 2000. Modellierung von Flexibilität in Architekturen industrieller Informationssysteme. in: Schmidt, H. 2000. Modellierung betrieblicher Informationssysteme. Proceedings der MobIS-Fachtagung. Siegen, p 125-145

Gronau, N. 2003. Wandlungsfaehige Informationssystemarchitekturen Nachhaltigkeit bei organisatorischem Wandel. Gito, Berlin

Hill, W., Fehlbaum, R., Ulrich, P. 1994. Organisationslehre 1: Ziele, Instrumente und Bedingungen der Organisation sozialer Systeme. 5 edn., Haupt, Bern, Stuttgart, Wien

Imai, M. 1993. Kaizen. Ullstein, Frankfurt a. M., Berlin

Kaib, M. 2002. Enterprise Application Integration: Grundlagen, Integrationsprodukte, Anwendungsbeispiele. DUV, Wiesbaden

Kieser, A., Kubicek, H. 1992. Organisation. 3 edn. De Gruyter, Berlin, New York Krcal, H.C. 2003. Systemtheoretischer Metaansatz fuer den Umgang mit Komplexitaet und Nachhaltigkeit. in: Leisten, R.; Krcal, H.-C. 2003. Nachhaltige Unternehmensführung - Systemperspektiven. Gabler, Wiesbaden, p 3-30

Krcmar, H. 1990. Bedeutung und Ziele von Informationssystemarchitekturen. Wirtschaftsinformatik 32, S. 395-402

Krueger, W. 1998. Management permanenten Wandels. in: Glaser, H.; Schröder, E.F.; Werder, A. v. (eds.) 1998. Organisation im Wandel der Märkte. Gabler, Wiesbaden, $\mathrm{p} 227-249$

Krystek, U. 1999. Vertrauen als Basis erfolgreicher strategischer Unternehmungsfuehrung. in: Hahn, D.; Taylor, B. (eds.)1999. Strategische Unternehmungsplanung - Strategische Unternehmungsführung. Physica, Heidelberg, p 266-288

Jurkovich, R. 1974. A core typology of organizational environments. Administrative Science Quarterly 19, p 380-394

Lang, K. 1997. Gestaltung von Geschaeftsprozessen mit Referenzprozessbausteinen. Gabler, Wiesbaden

Leavitt, H., Whisler, T. 1958. Management in the 1980s: New information flows cut new organization flows. Harvard Business Review 36, p 41-48

Lublinsky, B., Farrell, M. 2003. 10 misconceptions about web services. EAI Journal, p 30-33 
Markus, M., Robey, D. 1988. Information technology and organizational change: Causal structure in theory and research. Management Science 34, p 583-589

Narsu, U., Murphy, P. 2003. Web services adoption outlook improves. Giga Information Group

Oesterle, H. 1995. Business Engineering: Prozess- und Systementwicklung. 2 edn., Volume 1. Springer, Berlin et al.

Pohland, S. 2000. Globale Unternehmensarchitekturen - Methode zur Verteilung von Informationssystemen. Weissensee-Verlag, Berlin

Rockart, J.F., Short, J.E. 1989. IT in the 90's: Managing organizational independence. Sloan Management Review, p 7-17

Rombach, D. 2003. Software nach dem Baukastenprinzip. Fraunhofer Magazin, $p$ 30-31

Scheer, A.W.1991. Architektur integrierter Informationssysteme. Springer, Berlin Thom, N. 1996. Betriebliches Vorschlagswesen: ein Instrument der Betriebsfuehrung und des Verbesserungsmanagements. 5 edn. Lang, Berlin

Wall, F. 1996. Organisation und betriebliche Informationssysteme - Elemente einer Konstruktionslehre. Gabler, Wiesbaden 